This item was submitted to Loughborough's Research Repository by the author.

Items in Figshare are protected by copyright, with all rights reserved, unless otherwise indicated.

\title{
Visual repairables: analysing the work of repair in human-computer
} interaction

PLEASE CITE THE PUBLISHED VERSION

http://dx.doi.org/10.1177/1470357208099148

PUBLISHER

SAGE Publications (C) The Author(s)

VERSION

AM (Accepted Manuscript)

LICENCE

CC BY-NC-ND 4.0

\section{REPOSITORY RECORD}

Greiffenhagen, Christian, and Rod Watson. 2019. "Visual Repairables: Analysing the Work of Repair in Human-computer Interaction". figshare. https://hdl.handle.net/2134/13255. 
This item was submitted to Loughborough's Institutional Repository (https://dspace.lboro.ac.uk/) by the author and is made available under the following Creative Commons Licence conditions.

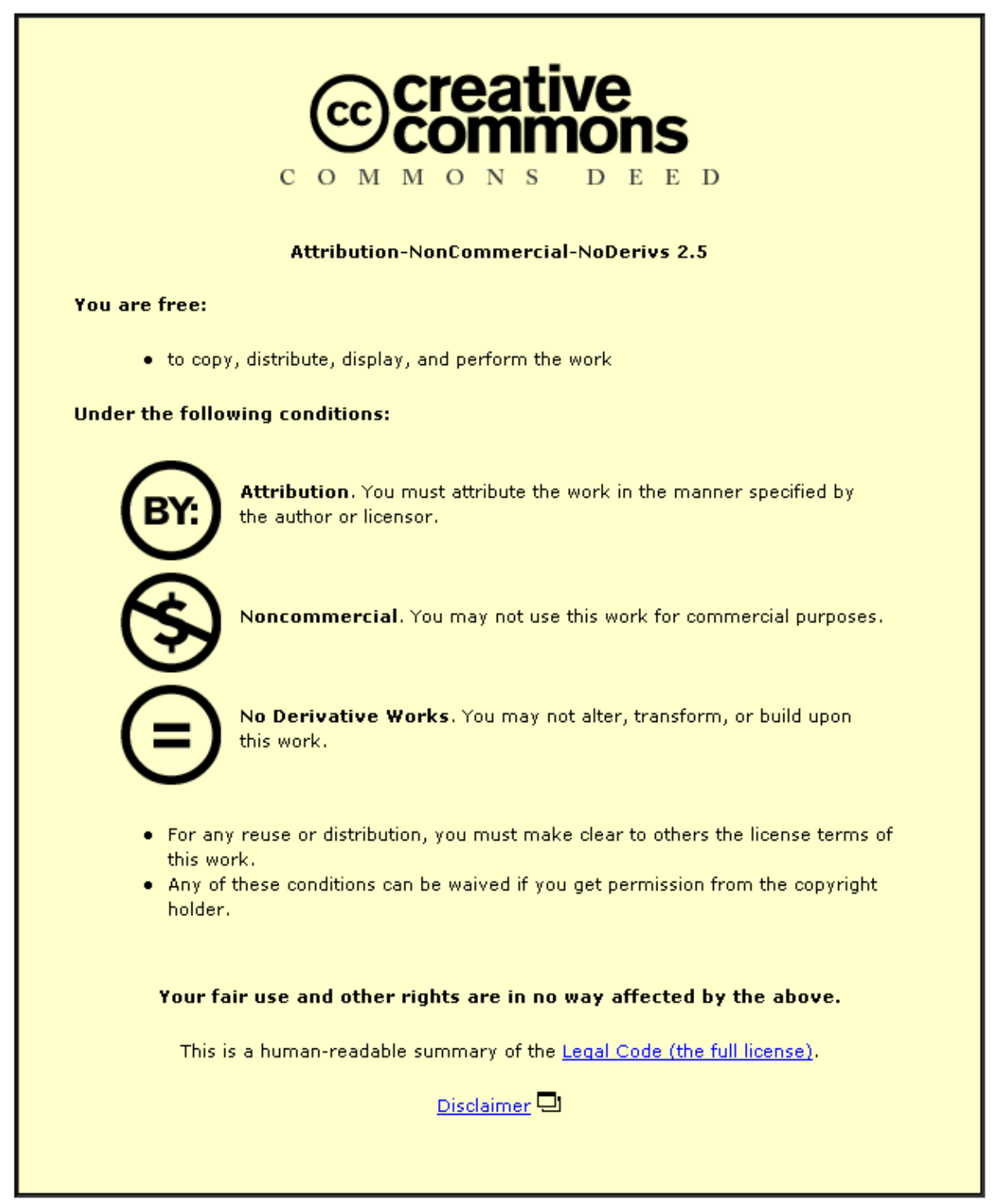

For the full text of this licence, please go to: http://creativecommons.org/licenses/by-nc-nd/2.5/ 


\title{
Visual Repairables: analyzing the work of repair in human-computer interaction
}

\author{
Christian Greiffenhagen and Rod Watson
}

Version: June 12, 2008

\begin{abstract}
This paper reports some (video-recorded) instances of 'visual culture' in action, namely the use of a new software tool designed for the visualization of scenes from Shakespeare's Macbeth in a classroom context. By considering whether or how far conversation analysis (CA) can be extended from natural conversation to cases of collaborative work in front of a computer, the paper addresses the methodological question of how to study instances of visual communication. We take as an exemplar the phenomenon of remedial action and discuss how the canonical study of repair in ordinary conversation (Schegloff, Sacks, and Jefferson, 1977) can be used to highlight aspects of 'visual repair' (the identification and remedying of items on the screen). Our attempts to apply the original CA model of repair of ordinary conversation highlight the differences of this setting, which constitutes an example of collaborative work.
\end{abstract}

Keywords. visual analysis; conversation analysis; human-computer interaction; repair; collaboration computer interaction. Visual Communication 8 (1), 65-90. 


\section{Introduction}

This paper aims to contribute to the burgeoning corpus of research on visual analysis (cf., Van Leeuwen and Jewitt, 2001; Rose, 2001; Banks, 2001). Drawing on both conversation analysis (CA) and ethnomethodology (EM), our goal is to contribute to the study of the systematic practices employed by participants in visual conduct.

Our case study is an example of what is now seen as the contemporary preoccupation with 'visual culture' (Evans and Hall, 1999). It studies the ways in which pairs of pupils use a new storyboarding software that was designed to help them with their study of Shakespeare's Macbeth. The software allows pupils to create their visualisation of a scene from the play as a series of storyboard frames. The pupils worked together in pairs and we analyse four instances of their collaboration in front of the computer.

In this paper we focus on the frequently-found phenomenon of 'visual repair', the identification and correction of things that perceivedly 'go wrong' for participants on the computer screen. Using the classical study of repair in natural conversation (Schegloff, Jefferson, Sacks, 1977) [SJS] as a methodological starting point, we bring out both the fruitfulness and the limitations of this approach. We find that although the original SJS study can help us to provisionally highlight certain features of our data, their central concepts are not always applicable to human-computer interaction, i.e., phenomena that do not constitute natural conversation. However, this does not comprise a surprising feature - let alone a criticism - of the SJS model so much as attest to the fact that the model is derived from, and designed for, ordinary conversation rather than collaboration at a computer in a classroom context. 


\section{Visual analysis}

Within the human sciences, there has been an emerging and increasingly pervasive concern with the visual dimensions of social life. These visual dimensions were first highlighted through the use of photographs and ethnographic film in anthropological fieldwork (e.g., Bateson and Mead, 1942). In the last few decades, the ready availability and rapid development of video technology potentiated a much more rigorous and wide-ranging approach to visual analysis.

Visual analysis concerns both a topic and a method of enquiry. It is often said (not always without reduction or hyperbole) that we live in a 'visual culture' (e.g., Evans and Hall, 1999). As a consequence, there has been an increasing concern both with 'visual objects' themselves, e.g., photographs (Jayyusi, 1993), CD-ROMs of novels (Jewitt, 2002), or toy houses (Brougère, 2006), as well as how objects and embodied conduct feature in interaction, e.g., practices of ‘professional vision’ (Goodwin, 1994; Goodwin and Goodwin, 1996), interaction around works of art in galleries (Heath et al., 2002), and collaboration and coordination in various work settings (e.g., Heath and Luff, 1992; Heath et al., 1995).

These new topics of enquiry have in turn raised new methodological questions. It was felt that many traditional methodologies (e.g., discourse analysis, semiotics, content analysis, conversation analysis) had been developed for the analysis of oral and textual phenomena, and that these could not directly be extending to the analysis of visual conduct and visual objects (cf., Norris, 2002; Flewitt, 2006). Rather than treating the visual as an 'add-on' to the oral or textual, the aim has been to develop approaches that do not start with a separation of the field into visual and verbal/oral elements, but that approach the phenomena under investigation in a more holistic 
fashion, treating them as a unified contexture (cf., Gurwitsch, 1964; Garfinkel, 2002). Thus while our data comprise oral (e.g., pupils talking), gestural (e.g., pupils pointing at objects at the screen), and visual (e.g., on-screen actions mediated through the keyboard or mouse) elements, these are not to be treated as separate 'channels', but instead as constituents of a unified configuration, where, if the identification of separable oral, gestural or visual elements is done at all, it is typically done (retrospectively) by analysts rather than the actual participants.

\section{Extending conversation analysis to visual phenomena}

CA has been a very fruitful approach to the analysis of 'naturally occurring' conversation (e.g., Sacks, 1992; Sacks, Schegloff, and Jefferson, 1974; Schegloff, Jefferson, and Sacks, 1977). Through the repeated analysis of small fragments of talk, CA aims to recover the methodic practices employed by conversationalists, such as ‘taking turns', 'repair and correction', and 'preference organisation'.

CA was developed as an analytic approach to study verbal conversation. However, a number of researchers have tried to extend CA to analyse non-verbal aspects of conversation, for example, the organisation of gaze in relation to turns of talk (Goodwin, 1981), or the timing of gestures in relation to the verbal utterances to which they are tied (Schegloff, 1984). The study of non-verbal features of conversation was further broadened to the analysis of the social organisation of embodied conduct and the role of artefacts in interaction. For example, studies of medical consultations exhibit how patients coordinate their utterances with the doctor's activities on the computer (Heath, 1986; Greatbatch et al., 1993). Other studies investigate how co-workers monitor each other's conduct and engage in 
activities without being explicitly prompted to do so (Heath and Luff, 1992; Heath et al., 1995).

The extension of CA has implied a changing role of transcripts. Gail Jefferson developed a transcription system (cf., Schenkein, 1978) that aims to capture the sequential features of conversation, and that provides the opportunity for readers not only to follow, but also to check out the analysis of the fragment (or even to pursue their own). Several researchers have attempted to extend Jefferson's transcription system to visual phenomena, for example, by including participants' direction of gaze (Goodwin, 1981; Heath, 1986), the typing on the keyboard (Luff and Heath, 1993), or the overall 'visual field’ (Goodwin, 2001; Heath et al., 2002). All these researchers acknowledge that no systematic transcription system is available for visual conduct and that their transcripts only capture selected aspects of the interaction. They also emphasise that the analysis is typically done primarily on the original videotape, rather than the transcript.

We follow in the tradition of these studies and try to extend the 'analytic mentality' of CA (Schenkein, 1978, p.1) to the study of visual phenomena. By speaking of 'analytic mentality' we draw attention to the fact that CA was explicitly developed for the study of verbal speech exchange and thus cannot be easily extended to the study of embodied conduct. However, we think that the use of naturally occurring data and the detailed of analysis of fragments can, with due caution, be extended to the study of embodied conduct, as can CA's attempt to exhibit how participants (rather than analysts) analyse each other's talk and conduct. That is to say, one of the central findings of CA was that the observed features of conversation (e.g., the 'no gap, no overlap’ rule) point to the fact that participants are analysing each other's utterances, computer interaction. Visual Communication 8 (1), 65-90. 
(for example, in order to anticipate a possible turn completion point). This emphasis on the analysis done by participants (rather than by sociologists) in our view shows the greatest potential for a contribution of CA to visual analysis (where participants' analysis not only concerns other people's verbal utterances, but also their visual conduct as well as features of the overall visual field). Finally, CA has led the way in treating many phenomena (e.g., that of 'understanding' or 'other minds') not as psychological, but as socially organised and practically accomplished phenomena. This emphasis on the social organisation of phenomena which are treated as based in participants’ shared cultural (methodic or procedural) knowledge again is a potentially productive contribution of CA to the study of visual conduct.

In extending the analytic mentality of CA to human-computer interaction (HCI) it is important to point out that in these situations the focus is not upon talk in itself, but upon the activity (in our case: constructing storyboards of Shakespeare's Macbeth). Furthermore, although the computer screen is the typical object of attention (i.e., oriented to by both pupils), the computer is not treated as a 'participant'. In contrast to early attempts to apply CA to the study of HCI, which treated the computer as a participant (cf., Luff et al., 1990), we investigate ‘human’-‘human’ interaction using a computer. That is to say, we do not consider the computer as a third party in the interaction, but instead investigate how the computer is being brought into the dyadic interaction. This is warranted because in our data we do not find pupils treating computers as 'real' participants. Instead, computers are incorporated by classroom participants into the intersubjective world of the classroom. Of course, this does not mean that teachers or pupils do not on occasion speak of computers 'understanding' what they want them to do or referring to what the computer 'means'. Anyone working with computers may sometimes talk in this way. However, when using computer interaction. Visual Communication 8 (1), 65-90. 
human predicates (e.g., 'understanding' or 'telling') when talking about computers in a vernacular way, participants common-sensically understand that these predicates are used in a figurative sense (cf., Button et al., 1995; Sharrock and Coleman, 2000). This, then, does not license any analytic reference to the computer as 'acting' or as possessing any of the predicates attributable to persons.

\section{Repair as a phenomenon in interaction}

Our topic in this paper is repair or correction, a prevalent phenomenon both in 'natural' conversation and 'visual' interaction. It therefore provides a good test case to extend the analytic mentality of CA from conversation to embodied conduct.

The canonical study of repair in natural conversation is Schegloff, Jefferson, and Sacks (1977) [SJS]. It is important to point out that for SJS what counts as an 'error' or a 'mistake' is not given by the psychological functioning of individuals, but instead constituted in and through the interaction between coparticipants. Moreover, the identification of an error is not to be understood as the prerogative of the analyst, but as the outcome of members' orientations as expressed in their work. In other words, not everything that could conceivably be characterised as having 'gone wrong' is treated as such by participants.

SJS employ the terms 'trouble-source' or 'repairable' for "that which the repair addresses” (p.363):

These range from inability to access a word when needed or to articulate it properly, to transient problems in hearing (e.g., due to ambient noise), to variously based problems of understanding; the 'variety of troubles' thus includes classes of problems, and a 
virtually unlimited array of ‘sources’ or 'causes’. (Schegloff, 1992, p.1341)

SJS are concerned with the sequential organisation of repair. They distinguish, firstly, between two classes of participants in relation to the repairable ('self' and 'other') and, secondly, two segments of the repair process itself ('repair-initiation' and 'repairoutcome'). They find that overwhelmingly often self-initiated repairs yield selfcorrection, and that other-initiated repairs also typically yield self-correction. Furthermore, SJS observe that other-initiations are marked as normatively dispreferred in a variety of ways, e.g., through holding off, 'cushioning', or mitigation. Finally, SJS remark upon clearly different initiator techniques by self and other. In particular, they mention that other repair-initiators (RI) can be ordered “based on their relative 'strength' or 'power' on such parameters as their capacity to 'locate’ a repairable” (p. 369; footnote 15).

Macbeth (2004, p.706) summarizes SJS in the following way:

As a course of action, repair shows both a sequential organization, or 'trajectory', and an organization of the parties to achieve it. A repair is first 'initiated', meaning roughly that a repairable is discovered and/or recognized as repairable, and then it is 'repaired', routinely - but not only - by its replacement.

Macbeth's formulation seems to us felicitous, since it foregrounds a crucial aspect of repair that we examine in this article, but which remains in the background in SJS's initial formulation. Macbeth, by saying that a repairable has to be “discovered and/or recognized”, begins to point to participants' work involved in repair-initiation. Furthermore, by noting that repair may involve activities other than simple replacement, Macbeth implies that the determination of what will count as a repairoutcome also involves members’ conjoint work. In our view, any study of repair work computer interaction. Visual Communication 8 (1), 65-90. 
will thus involve scrutinizing the distinctively identifying details of this repair, here and now.

\section{Repair in human-computer interaction}

Just as there are 'trouble sources' in conversation, so there can be trouble sources in embodied conduct in general, and human-computer interaction in particular. It is tempting to extend SJS's analysis of repair from troubles sources in talk to trouble sources with the computer, i.e., to what participants can see on the screen. However, this is a definite departure in its terms of reference from the intentions of the original and subsequent articles, where the examples were drawn exclusively (and selfavowedly) from oral-aural interaction, i.e., they exhibited participants' troubles with “understanding what someone has just said” (Schegloff, 2000, p.207; our emphasis). That is to say, SJS are concerned exclusively with oral-aural interaction, whereas in our case repair work has to do with participants' troubles in understanding what someone has just witnessably and visibly done on the screen. However, we took encouragement from SJS's observation that “nothing is, in principle, excludable from the class 'repairable'” (p.363), though they only had in mind troubles in ordinary conversation.

One of the earliest attempts to apply CA to HCI was Frohlich et al. (1994). They extended SJS's analysis of 'human'-'human' conversation to 'human'-‘computer' interaction., where the user's input on the keyboard is treated as a turn, as is the computer's 'response' on the screen. Moreover, mutual understanding among humans is extended to 'understanding' between human and computer. For example, Frohlich et al. observe: 
Getting the computer to recognize what you mean is considerably more difficult than the comparable activity in conversation. (p.415)

They identify a typical sequence:

- $\quad$ user's turn (which turns out to be problematic);

- computer’s error message or unexpected response;

- user's repair.

While we find the overall analysis of Frohlich et al. often illuminating, we think that they gloss over the question in which sense a computer's error message is akin to a co-participant's utterance in the case of human-human conversation. Rather than taking the computer as showing elements of 'participation', we therefore investigate how two users establish mutual understanding via and through the computer.

Other authors have used the turn-taking model or the repair model as a set of empirical propositions which can be verified or falsified in a positivistic or formal analytic manner (on 'formal analysis', see Garfinkel, 2002). They seek to bring empirical confirmation or disconfirmation to bear on essentially abstract propositions, rather than on the local phenomenal detail of context. They thus begin with the assumption that the conversational turn-taking system is an appropriate tool with which to conduct their analysis of circumstances outside everyday conversation, and then find it wanting when it purportedly inadequately accounts for their data (e.g., Herring, 1999; Garcia and Jacobs, 1999). We have criticized this misuse of the turntaking model in a recent paper, in which we also point out that Sacks, Schegloff, and Jefferson (1974) emphasize that their model for turn-taking is function-specific and disparities across media are therefore to be expected. Thus in our view, those computer interaction. Visual Communication 8 (1), 65-90. 
subsequent authors' mistaken extension is not licensed by the initial conception of simplest systematics as a turn-taking system for natural conversation.

We thus do not start with the SJS vocabulary because we are committed to their model or because we are making a priori assumptions that they have a systematic empirical relevance for our data (even SJS do not present their model as definitive for their own order of data). Instead, we employ the SJS model heuristically to assist us in the initial and tentative explication of our data, as 'aids to a sluggish imagination' (cf. Garfinkel, 1967, p.38).

\section{The setting}

Our video fragments are taken from classroom situations in which pupils (aged 13-14 years) used a new high-specification software called 'kar2ouche'1 . This software was used in the context of English lessons which took place in an ICT suite in a British secondary school. Kar2ouche was developed as part of the Oxford-Intel Education Initiative, a collaborative project between educationalists, teachers, and software designers. As part of the Initiative, we conducted video-based observational studies of the software's impact on teaching and learning (see, e.g., Birmingham, Davies, and Greiffenhagen, 2002; Greiffenhagen, forthcoming).

The fragments analyzed in this paper depict pairs of pupils working with the software as they study for their Key Stage 3 national tests in English, an examination every pupil sits at fourteen and which always contains questions on a play by Shakespeare.

\footnotetext{
${ }^{1}$ http://www.immersiveeducation.com/kar2ouche/
} computer interaction. Visual Communication 8 (1), 65-90. 
The software allows them to produce storyboards of Macbeth, the chosen play this particular year.

[Figure (a) here]

Pupils use the software (see the interface in Figure a) to visualize a specific scene from William Shakespeare's Macbeth in a series of frames. They build their frames in the construction window in the middle of the interface. A frame is constructed by selecting a background, characters, and props; choosing a pose for the characters; attaching speech and thought bubbles to them; and finally typing reasons in the caption box. Finished frames join others in the thumbnail bar above the construction window.

After the teacher had introduced the software and told the class what they should do, pupils would work in pairs on a specific scene of Macbeth (which they completed over five lessons in the computer suite). We observed different forms of collaboration, which included, (a) one pupil using both keyboard and mouse ('user') while the other pupil had no direct access to the computer ('helper'), and, (b) one pupil in control of the mouse (and thereby being in charge of, e.g., selecting the frame to work on, inserting characters or speech bubbles, as well as moving and resizing these) and the other pupil in control of the keyboard (and thereby being in charge of typing in the speech and thought bubbles, as well as the caption box below the frame). Pupils working in format (a) would often switch 'roles' from lesson to lesson. 


\section{Analysis}

We now want to illustrate the above remarks by reference to four transcribed data fragments, which are treated as perspicuous examples for methodological purposes (rather than as a collection for systematic comparison).

\section{Fragment 1: 'you can't do it like that'}

[Figure (b) here]

In this fragment, Naomi (all names have been anonymized) on the right is constructing a new frame of their storyboard. She has copied some text (that will end up in the speech bubbles) into the caption box and has selected a background picture. She is in the process of inserting the character of Macbeth.

Having said "ts get you down here” (line 1), Naomi tries to drag and drop Macbeth from the thumbnail of the last completed frame into the current frame (in order to have Macbeth in the same pose as in the previous one). In the transcript, we have tried to capture this ‘drag and drop' movement with a white directional arrow and two circles (for the starting point and end point). However, Naomi's 'drag and drop' action does not work, since the software does not provide for this. So when Naomi releases the mouse button (end of line 1), Macbeth does not appear in the construction window. Immediately after releasing the mouse button, she exclaims: "oh no you can’t do it like that (.) can yah" and Sally on her left laughs. Naomi says "oh dear” and goes on to bring Macbeth across from the character window instead, and then proceeds to change his pose manually.

This fragment shows how the SJS model, considered as a heuristic device, can elucidate our data from this setting. Although the trouble source, the failure of computer interaction. Visual Communication 8 (1), 65-90. 
Macbeth to appear in the frame upon release of the mouse button, is an on-screen event, the two original distinctions (self/other and initiation/outcome) still work to describe this fragment. The repair is initiated by current doer (self) through the verbal utterance "oh no", and then effectuated by self in the next turn after the repairable. This fragment could thus be seen as something like the 'computer-equivalent' of a mistake of grammar, where SJS remark:

when 'errors' of grammar are made and repaired, the repair is usually initiated by speaker of the trouble source, and rarely by others (p. 370; footnote 16).

As a general observation we found that in our data that when something went visibly wrong on the screen, it was overwhelmingly the doer of the trouble-source who effectuated the repair.

In that sense Naomi's utterance “oh no you can’t do it like that” could be heard as a comment on her own work. She thereby marks the events on the screen as what we might call a 'production error' (following, and extending, Jefferson, 1974). Note that Naomi does not attribute the source of the error to her incompetence (e.g., "I can’t do it ... because I haven't learnt how to.”), but instead to the technical limitation of the software. In other words, it is not just Naomi who “can’t do it like that" but 'everyone' - everyone in Sacks’s (1975) technical sense. Thus, we could say that the error (trouble-source) is here produced by the current doer (self), where the source of the error is not attributable to self, but is a feature of the software. We might note that there is an ambiguity in applying SJS's term 'producer of trouble-source' to this fragment: on the one hand, Naomi is the 'doer' (and thereby producing the troublesource); on the other hand, the origin of the trouble is not Naomi's own production, but a feature of the software. computer interaction. Visual Communication 8 (1), 65-90. 
For this fragment, the SJS model has helped us to bring the phenomenon of visual repair to notice. The analysis thus exhibits how the SJS model can be used as a (contrastive) 'aid to sluggish imagination'.

\section{Fragment 2: 'load-save’}

[Figure (c) here]

In this fragment, the pupils want to save the work they have done so far. In order to do so, Bob (on the right) switches from the construction screen to the utilities screen by clicking on the red button at the bottom right corner of the interface, identified as '(4) utilities' in Figure (a) above. In the transcript, we have emphasized the position of the mouse pointer by a white circle. Note that in the utilities screen there are two red icons: the icon above the folder is for load (importing), the icon below the folder is for save (exporting).

Having switched to the utilities screen, Bob moves the mouse pointer to the load icon and clicks on it (end of line 2). Immediately Shawn says "no:: (.) save” (beginning of line 3). Bob clicks on 'cancel' and then selects the save option.

As with the first fragment, we think the SJS model can be used as heuristic device to explicate some of the aspects of the social organization of pupils' conjoint actions, which could be initially described as an other-initiated self-repair.

In this fragment, rather than pressing the icon to save the current storyboard, Bob has pressed the load button. This is identified as a trouble source by Shawn's utterance “no:: (.) save”, which thus constitutes a repair-initiation by other. As SJS remark: “The techniques for other-initiation are techniques for locating the trouble source.” (p.377). Furthermore, Shawn's utterance not only indicates the trouble-source but computer interaction. Visual Communication 8 (1), 65-90. 
owing to the simple layout of the screen, also indicates a repair outcome, i.e., it is as if he were saying "you need to save and not load".

Shawn only initiates the repair but does not attempt to perform the repair himself by taking control of the mouse. This could be seen as normative preference for self-repair over other-repair as an ordinary conversation. However, in this situation, the overall arrangement also constitutes a different ecological 'affordance' (Gibson, 1979) in comparison to ordinary conversation. That is to say, self and other do not have equal access to the trouble source, given that at any particular moment only one participant has control of the mouse. By contrast, in ordinary conversation both participants can speak on an equal participation basis, i.e., any one of them can initiate and perform any conversational action.

In other words, initiation in the situation we are studying can be done by either pupil and therefore the SJS model is putatively applicable to this aspect. For example, SJS mention a preference for self-initiation over other-initiation, so the fact that Shawn holds off his utterance (for about half a second after Bob has pressed 'load') may display his orientation to such a preference. In contrast, for the shaping of the effectuation of the repair there is both an asymmetrical ecological distribution (spatial positioning of pupils in relation to the mouse) and a normative division of labour (typically one pupil has control over the mouse for one phase of the task). So while we think that Shawn's utterance “no:: (.) save” can be characterised as an otherinitiation (in relation to self selecting 'load), it is far less clear that self-other distinction pertains to the effectuation phase of the repair.

Notice that in two fragments so far analyzed the nature of the initiation and repair is entirely routinized and unproblematic for participants. That is to say, the ongoing computer interaction. Visual Communication 8 (1), 65-90. 
activity in which the pupils are engaged in (inserting a character or saving the storyboard) does not break down and is not compromised in any way that needs to be rendered further attendable by participants.

\section{Fragment 3: 'poor past'}

[Figure (d) here]

Shawn (on the left) is typing in the caption box underneath the construction window. In the caption box, he is describing what is happening in the frame. He is in the process of typing, "Macbeth is guilty and he knows it. Lady Macbeth is reflecting on her poor past”. In the transcript, we have tried to capture what Shawn is typing as he is talking. So, for example, he types his last word "past" and presses the space bar (represented by an empty square $\square$ ) just before he says “past”. Furthermore, in the transcript we have numbered five frame grabs and shall henceforth identify them through square brackets [1] to [5].

Immediately after typing "poor past” and pressing the space bar, Shawn moves his hand away from the keyboard [2]. Roughly two seconds later, Bob (on the right) brings his hand in above the backspace key [3]. After hovering briefly above the backspace key, Bob retreats his hand halfway, still above the keyboard [4]. Shawn then brings his hand back to the keyboard, also towards the backspace key [5]. Finally, Bob takes his hand completely away, asking "Is that it?" to which Shawn answers “Yeah”, before pressing backspace $(\mathcal{U})$ and full stop $(\bullet)$.

Observe that at the point at which Shawn is withdrawing from the keyboard, the sentence in the caption box is followed by a space (this space is visible in the caption box at the bottom of the transcript, after the ' $t$ ' of "past" and before the black vertical computer interaction. Visual Communication 8 (1), 65-90. 
bar cursor). The sentence thus appears to be either an unfinished sentence, which will be continued, or a finished sentence, which stands in need of correction by first pressing the backspace and then the full stop keys.

Provisionally, this fragment could be characterised as an example of an other-initiated self-repair. Whereas in Fragments 1 and 2 the initiation is done verbally, here it is (at least, initially) done gesturally.

In more detail; Shawn's withdrawal from the keyboard can be seen as displaying that he has arrived at a completion point. Notice that Shawn not only sits back, but also moves his left hand towards his face in what one might, in vernacular terms, characterize as a 'reflective' or 'contemplative' (i.e., not 'proactive') mode [2]. His withdrawal lasts roughly a second and is followed by a two second pause during which neither participant takes a turn. After this pause, Bob moves his hand towards the backspace key [3], leaves it there for 0.2 seconds, before moving it back halfway [4]. In response to Bob's hand movement, Shawn brings back his hand to the keyboard toward the backspace key [5].

Bob’s moving his hand towards the backspace key can be seen as an other-initiation, albeit (at first, at least) one performed gesturally (visibly) rather than verbally. It transforms the sentence on the screen into a repairable. Again, we find as SJS say: “The techniques for other-initiation are techniques for locating the trouble source.” (p.377). However, Bob is not directly locating the potential repairable, i.e., he does not point at the caption box on the screen (where the repairable is to be found). Instead, he moves in the direction of the backspace key on the keyboard, a move rendered sensible for the participants in relation to the incomplete sentence in the caption box on the screen. That is, the initiation is done with some indirection: the computer interaction. Visual Communication 8 (1), 65-90. 
repairable is on the screen, whilst the initiation is done on the keyboard (which, of course, has a connection with what is, or what should be, on the screen).

Bob does not press the backspace key, i.e., he does not perform the other-repair as such. Instead, having moved toward the backspace key [3], Bob partially withdraws his hand so it continues to 'hover' above the keyboard [4]. This works gesturally as something akin to a 'correction invitation device’ (Jefferson, 1972). Furthermore, Bob, with his hand still hovering above the keyboard, asks “Is that it?”, an utterance that through the questioning intonation has some elements of try-marking built into it (cf., Sacks and Schegloff, 1979, p.18). "Is that it?” thus works as an oral 'correction invitation device’. In sum, Bob produces two RIs: firstly, a gestural one (moving his hand towards the backspace key), and secondly, an oral one (asking “Is that it?”). We think that the two could be regarded as a 'reflexive' action where each elaborates the other (cf., Garfinkel and Sacks, 1970).

Through these repair initiations, Bob indicates two possible repair trajectories: either Shawn has finished typing in the caption box and so needs to put a full stop at the end of the sentence, or he has not and so should continue typing. Note that had Bob pointed at the space at the end of the sentence on the screen (instead of moving his hand toward the backspace key), this would also have identified the same trouble source as well as indicating the same two possible trajectories for correcting that incomplete sentence (either pressing backspace and then full stop, or continuing the sentence). However, Bob's actual gesture towards the backspace key not only identifies (for the two parties) a trouble source, but also suggests a normative preference for one of two candidate repairs (namely pressing the backspace key and then full stop rather than continuing the sentence). 
We want to comment on another aspect of Bob’s gestural repair initiation that shows the fruitfulness of SJS's notion of relative 'strength' or 'power' of different types of repair-initiator (in terms of their capacity to locate a repairable) with respect to this data. To draw out this aspect it is helpful to compare this fragment with the last one. In both fragments the repairable is on the screen, i.e., a visual object. However, whereas in the last one (Fragment 2) the other-initiation was done verbally, here the other-initiation is done gesturally, at least at first. Other-initiations of visual trouble sources can thus be done both verbally and gesturally. Furthermore, it seems that both other-initiations in Fragments 2 and 3 are of comparable 'strength' in terms of locating the trouble-source (on one hand saying "save”, on the other moving towards the backspace key).

For these two instances, we should however like to note a difference between the strengths of oral and gestural RIs in identifying a trouble source on the screen. This has to do with the overall configuration of the screen and the ability of a verbal RI to 'pick out' or indicate a potential trouble source. In Fragment 2, the pupils are looking at a very simple screen layout, basically only incorporating two options, load and save. Consequently, saying "no:: (.) save” is an adequate (for all practical purposes) verbal RI to identify the trouble source and indicate a repair trajectory. In contrast, the configuration of the screen in Fragment 3 is considerably more complex. Had Bob only asked orally “Is that it?”, his utterance could be understood by Shawn in a variety of ways. For example: "Do you want to add anything to the actual picture (e.g., add a prop, change the size of a character, or insert another speech bubble)?”, “Have you finished typing in the caption box?", or even "Have we finished for today?”. In other words, had Bob only performed an oral initiation (as Shawn does in 
Fragment 2), this would approximate to what Drew (1997) has called an ‘open’ repair initiator, which

leave[s] open what exactly the difficulty is which the speaker (i.e., the one who initiates repair) is having with the other's prior turn (p.72).

In contrast, Bob’s actual gestural initiation does specify the difficulty with Shawn's prior turn (namely the incomplete sentence). In sum, whereas in Fragment 2 a verbal initiator alone identifies the trouble source, in Fragment 3 it might not as easily have done so. The reason for this is that participants see screens configurationally (cf., Hester and Francis, 2003, p.41) and the screen layout in Fragment 2 affords fewer options of what to do next with the displayed objects.

Again, the SJS model has helped us to elucidate aspects of this fragment. However, we want to note that in a certain sense what constitutes the trouble-source or repairable is an emergent phenomenon. For SJS, it seems that the locating of the trouble-source is 'direct' and instantaneous, whereas in our data locating the troublesource may involve more collaborative work and the repairable may be 'worked up' over the course of the repair. In our final fragment, what will count as an 'outcome' is similarly collaboratively produced.

\title{
Fragment 4: 'you don't do that much'
}

\author{
[Figure (e) here]
}

The pupils in this fragment see their task as visualizing the whole scene, i.e., they will make sure that every line of dialogue will appear in a speech bubble. For each frame of the storyboard this means that the pupils have to determine where to start and where to end in the text of the play. 
In line 1 of the transcript, Naomi (on the right) is reading through the speech bubbles of the previous frame in order to find out where they have got to so far (and where therefore to start in the new one). It turns out that the first line of the new frame needs to be “as I descended”, which Sally (on the left) has already pointed out previously ("which is what I said”, end of line 1). The next task then is to determine the end point of the dialogue for this frame. In line 2, Naomi uses the mouse to begin highlighting the text that they will include in their next frame (starting with "as I descended”). In the transcript we have tried to capture how much text is highlighted in the text window at key moments. The steps to notice in the transcript are these:

- Naomi begins highlighting text and stops only when she reaches the bottom of the text window (line 2).

- At the point at which Naomi has marked the text up to halfway down the text window, Sally says “You waste time, you don’t do that much” (line 2). At the end of Sally's utterance, Naomi has reached the bottom of the window, having highlighted five lines of dialogue.

- A second later (end of line 2), Naomi deselects the last two of these five lines, leaving three lines highlighted. Naomi simultaneously asks: "How much we doing then for this one?” (lines 2-3)

- In response to Naomi’s question, Sally answers “four” (line 3).

- Naomi reselects one line, taking the total of highlighted dialogue to four lines (beginning of line 3). 
Following this, Naomi leaves the mouse (middle of line 3). In turn, Sally extends her hand towards the screen (middle of line 3) and starts counting the highlighted lines aloud: one, two, three, and so on. Just as she says "three”, Naomi presses CTRL and $\mathrm{C}$, in order to copy the four lines of dialogue she has highlighted (so they can be pasted later into speech bubbles). Sally (still counting the lines) then reaches the bottom of the text window and asks Naomi to scroll down slightly so that she can see what text comes next (beginning of line 4). Naomi scrolls down (middle of line 4) allowing Sally to continue counting. Sally completes this episode by saying "yeah just leave it at four” (end of line 4).

As a first move, we would characterize this episode as an other-initiated repair. In the previous two fragments other-initiation repair activities have included two aspects: firstly, an identification of a trouble source, and, secondly, an indication of a 'desired' outcome of the repair. In this instance, Sally's "You don't do that much" also clearly indicates a trouble-source (namely the highlighting of too much text). Furthermore, this verbal RI is high in its 'strength' in locating a trouble source, as it clearly relates to what Naomi is currently visibly doing on the screen, namely marking text. "Is that it?” in Fragment 3 has less 'power' in this respect. However, Sally’s utterance does not contain any indication of a desired repair-outcome, except that it should be less than the currently marked text. Again, compare with Fragment 3, where Bob’s move towards the backspace key did indicate a repair-outcome (understood as what might count for participants as an adequate repair).

Whereas the previous fragment highlighted the work involved in the identification of the trouble-source, the current fragment exhibits that the arrival at an appropriate outcome also involves work. What this example shows is that in this situation, computer interaction. Visual Communication 8 (1), 65-90. 
'outcome' is a gloss for what the conjoint work of repair (what we have called the effectuation) will have come to. In other words, producing the repair-outcome can itself take on a course-of-action form, rather than, e.g., being tied to a single utterance or other action. In this fragment, there is no clear view what the correct outcome might be until Sally says “yeah just leave it at four”. Of course, throughout the repair sequence an 'outcome' of sorts is in view ("less”), but what that outcome will be specifically is not made clear by either of the two pupils: it could be two, three, four, or five lines. In sum, the repair procedure begins without the participants displaying what it is that will stand as a correct outcome for them.

It is relevant here to make an observation on the uses of the personal pronoun "you" in Sally’s utterance "You waste time you don't do that much". The first "you” is hearable (by Naomi and by us) as a comment on what Naomi is doing (i.e., "you” used as an address term). However, the second "you" seems to us to have a different character. It does again comment on what Naomi is doing (as an address term). However, the "you” seems also hearable as 'one' or 'we', i.e., as exhibiting that the production of the storyboard is their common task (see Sacks, 1992, Fall 1966, Lecture 11, and Watson 1987 for the 'in principle ambiguity' of “you”). This ambiguity can also be found in the attempt to determine whether this is an instance of self-repair or other-repair. Sally’s utterance seems to be an unproblematic otherinitiation. However, is what follows a self-repair or an other-repair? On the one hand, after Sally says "You don’t do that much”, Naomi deselects two lines of text. Is it therefore a self-repair? On the other hand, it is Sally’s utterance “four” in response to Naomi’s question “How much we doing then for this one?” which will ultimately be accepted as the repair. So is this an other-repair? 
Perhaps what this points is that although the SJS model can be used as a heuristic device to highlight aspects of our data, the overall activity is far removed from the ordinary conversational activities to which the SJS model is addressed. Thus rather than trying to adhere to and adapt the concept of self and other, we might characterize the whole of the interaction after Sally says "four" as comprising conjoint "ratifying work', i.e., arriving at a mutual agreement that four is a good outcome. By pressing $\mathrm{CTRL}+\mathrm{C}$ and copying the four highlighted lines of text (middle of line 3), Naomi is offering a candidate repair-outcome, which is only ratified after Sally finishes counting six more lines and says, long afterwards, “yeah just leave it at four” (line 4). In other words, in this fragment arriving at a repair-outcome is something that is collaboratively produced.

We might characterize what is happening here as an instance of 'team collaboration'. The importance of this collaborative aspect in our data can not be gainsaid, since it points to the difference between ordinary conversation and a task-oriented activity. In the former, an utterance might be conceived as 'owned' by its speaker. This 'ownership' is the precondition of a strong delineation of self and other with respect to a particular trouble-source. By contrast, our situation is an instance of a collaboratively performed task. An action which is performed on the screen is of course done by one coparticipant, but that person does not necessarily 'own' the outcome of that act, which is subsumed under the task which will be a conjoint product. This means that the self-other distinction is greatly attenuated as an organisational property of the interaction.

As we have observed above, the fact that this is a collaboration does not necessarily mean that the coparticipants are always of equal status. For example, there may be computer interaction. Visual Communication 8 (1), 65-90. 
asymmetries with respect to technical competence, knowledge of the play, general experience, or access to the keyboard (through keyboard or mouse) - where these have to be understood as oriented-to and occasioned matters. Thus in this fragment there is a visible asymmetry between Sally and Naomi. Naomi’s utterance "How much we doin' then for this one” exhibits an element of deference (in relation to this particular activity) towards Sally. Similarly, Sally’s “one, two, three, four, go down” is hearable as instructing Naomi and thereby demonstrating her greater competence and authoritativeness with respect to the current activity.

In this fragment, we thus can see the problems of extending CA directly to instances of visual conduct. It seems that one of the most fundamental categories, the self-other distinction, cannot be used in all instances of collaboration, since the products of individual participant's actions are not 'owned' by them. However, this does not mean that CA can not be a fruitful tool for visual analysis. We think that the emphasis on participants' endogenous analysis of the situation (rather than analysts' external analysis) has been illuminating throughout our discussion of this fragment. Although it was possible to characterise Naomi's and Sally's action as self or other, we have shown that it is still they who establish whether something is in need of repair and what a possible outcome should be.

\section{Conclusion}

Across these four instances our aim has been to explore if and how CA could be extended to the analysis of human-computer interaction to see where such an extension might lead and what its limitations might be. We chose the phenomenon of repair as a test case, since it seems to occur both in ordinary conversation and interaction with computers. 
Throughout the analysis the SJS model has on occasion been a fruitful heuristic device to highlight aspects of the interaction. In particular, the distinction between 'initiation' and 'outcome' proved useful mutatis mutandis on several occasions. However, while for SJS both of these are often seen as virtually instantaneous and straightforward, our instances led us to emphasise that these may involve considerable work for participants. We have thus pointed to the effectuation of repair, where both the location of a trouble source and the identification of an appropriate outcome may have to be collaboratively achieved. Finally, we have indicated that other-initiators do not only differ in their strength in locating a trouble-source (as SJS remark), but may also differ in their strength in indicating a preferred repair-outcome.

Despite the occasional usefulness of the SJS model, applying the self-other distinction to our data sometimes proved to be problematic. The reason for this is that the two pupils are engaged in a collaborative project; they are building something together. As a consequence, although each action is still identifiable as being done by one of the two, the product of that action does not necessarily 'belong' to that doer. In contrast, utterances are typically 'owned' by their enunciator, especially in the case of someone telling a story.

Repair in ordinary conversation is tied to the achievement of shared, specific understanding. However, there is an asymmetry in the socially-organized practices involved in achieving of such understanding or alignment, since one co-participant has to gain an understanding of the other. That is to say, in ordinary conversation, other-initiation may occur when 'other' is not quite able to understand (in the alignment sense) what 'self' has just done. In contrast, in these instances of 
'teamwork', it is not so much that one of the pupils has problems 'understanding' the other, but raises issues about what they both trying to achieve.

We have mentioned the importance of both ecological features of the situation as well as a division of labour. On the one hand, it is only possible to correct errors on the screen if one is positioned to have access to the keyboard or mouse (in contrast to 'verbal' errors where the potential correction has no such ecological aspects). Thus the physical layout of keyboard and mouse, as well as the positioning of pupils provide for differential access to influencing the objects on the screen. Moreover there are some constraints that are intrinsic to the software (e.g., that in the first fragment Naomi cannot drag the character from the thumbnail bar into the composition window). However, even more important than these ecological features is the occasioned ‘division of labour’ (Anderson et al., 1991) visible in these fragments. For any particular segment of the task (e.g., the construction of the picture or typing in the caption box below the picture) it is typically only one pupil who uses the mouse or keyboard during this segment. Although the other pupil may comment, correct, or agree to what is being done, the keyboard and mouse are still consistently used (during this segment) by the other pupil.

This division of labour is oriented-to by pupils and can become quite pronounced. For example, after the unsuccessful attempt to copy Macbeth from the thumbnail bar (Fragment 1), the following exchange occurs:

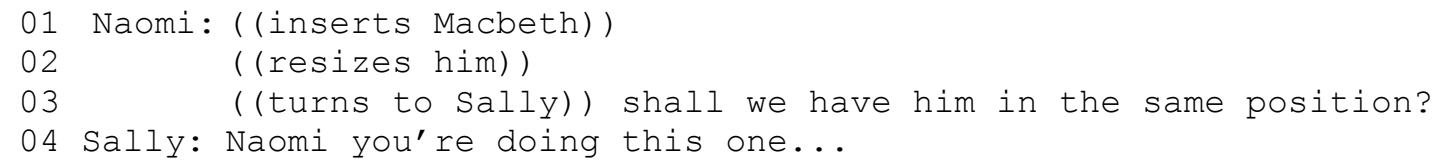


Here not only does Sally not take the mouse, but she even refrains from helping Naomi with the current decision on the grounds that it is Naomi's role to complete this segment of the task. As an oriented-to phenomenon this division of labour introduces new normative considerations. In ordinary conversation, self and other pertain to the ownership of utterances and the normative preference for self-repair. Here, self and other considerations do typically not apply to the product of actions (since the outcome of the activity is a common product), but may apply to the responsibility of completing a particular segment of the task.

All these considerations point to the importance of treating these fragments as instances of 'teamwork'. In particular in the last fragment, rather than asking whether it is self or other who finally identifies what will count as a repair-outcome, we may characterise this as the pupils collaboratively 'getting to' (Schenkein, 1971, Chapter 2) a mutually agreed outcome. For Schenkein, 'getting to' is not organized in terms of self and other but in terms of collaboratively arriving at a particular point in a salesman-client interaction. Adapting his concept for our purposes, we might want to say that the two pupils are getting to a mutually agreed outcome of the repair process. In other words, the pupils are methodically establishing and maintaining a joint orientation to something (e.g., “what we are doing” or “what we are talking about”). This involves what Goffman (1979, p. 35) terms a ‘collaboration of hands’ and might also be expressed through the colloquial expression 'being on the same page'.

With respect to the question of applying CA to the analysis of HCI these considerations suggest that rather the wholesale transposition of a model of conversation, we should be thinking instead of bringing to bear the 'analytic mentality' of this approach. We think that two elements could prove especially computer interaction. Visual Communication 8 (1), 65-90. 
helpful, first, an emphasis on participants as analysts, and, second, a resulting treatment of phenomena in a non-cognitivistic, praxiological manner. That is to say, we have tried to emphasize that the features of collaborative work at the computer are oriented to by participants. Furthermore, by emphasizing pupils' culturally-based sense-making practices, we have treated repair not as a psychological, individual phenomenon, but as a socially-organized one.

In the sphere of visual interaction issues of (ethnographic) 'context' are very likely to emerge. However, the question is not so much whether to include contextual features in the analysis, but how this may be done. Thus it seems clear that in these fragments the general classroom culture, the specific task (what the teacher has told pupils to do), the physical layout of the room, and the individual differences between pupils (including, the degree of pro-activeness of each pupil, their knowledge of the play, as well as their technical competence) all have a potential bearing on each analyzed instance. Whether they become salient to the particular case is a strictly occasioned matter, and the challenge would then be to exhibit whether and how these issues enter into pupils' practices and the 'participation framework' (Goffman, 1981) within which these practices take place.

\section{Acknowledgements}

We are most indebted to the teachers and pupils who allowed us to spend an extensive time in their classrooms, as well as the people at Immersive Education for their help with setting up kar2ouche. An earlier version of this paper was presented at the International Institute for Ethnomethodology and Conversation Analysis (Manchester, July 2-4, 2003) and we would like participants for their comments and criticisms. We are grateful to Peter Birmingham with whom we started the work on this paper and computer interaction. Visual Communication 8 (1), 65-90. 
would like to thank Douglas Macbeth and the anonymous reviewers for helpful comments and criticisms on earlier versions of this paper. Christian Greiffenhagen acknowledges the support of the British Academy through a Postdoctoral Fellowship.

\section{References}

Anderson, R. J., W. W. Sharrock, and J. A. Hughes (1991). The division of labour. In B. Conein, M. de Fornel, and L. Quéré (Eds.), Les formes de la conversation: Volume 2, pp. 237-252. Issy-les-Moulineaux: Centre national d'études des télécommunications.

Banks, M. (2001). Visual Methods in Social Research. London: Sage.

Bateson, G. and M. Mead (1942). Balinese Character: A Photographic Analysis. New York: New York Academy of Sciences.

Birmingham, P., C. Davies, and C. Greiffenhagen (2002). Turn to face the Bard. Education, Communication \& Information 2 (2/3), 139-161.

Brougère, G. (2006). Toy houses: a socio-anthropological approach to analysing objects. Visual Communication 5 (1), 5-24.

Button, G., J. Coulter, J. R. E. Lee, and W. W. Sharrock (1995). Computers, Minds and Conduct. Cambridge: Polity Press.

Drew, P. (1997). 'Open' class repair initiators in response to sequential sources of troubles in conversation. Journal of Pragmatics 28 (1), 69-101.

Evans, J. and S. Hall (199). Visual Culture: The Reader. London: Sage.

Flewitt, R. (2006). Using video to investigate preschool classroom interaction: education research assumptions and methodological practices. Visual Communication 5 (1), 25-50.

Frohlich, D., P. Drew, and A. Monk (1994). Management of repair in humancomputer interaction. Human-Computer Interaction 9 (3/4), 69-101.

Garfinkel, H. (1967). Studies in Ethnomethodology. Englewood Cliffs, NJ: PrenticeHall.

Garfinkel, H. (2002). Ethnomethodology's Program: Working Out Durkheim's Aphorism. Lanham, MD: Rowman \& Littlefield.

Garfinkel, H. and H. Sacks (1970). On formal structures of practical action. In J. C. McKinney and E. A. Tiryakian (Eds.), Theoretical Sociology: Perspectives and Developments, pp. 338-366. New York: Meredith.

Garcia, A. C. and J. B. Jacobs (1999). The eyes of the beholder: understanding the turn-taking system in quasi-synchronous computer-mediated communication. Research on Language and Social Interaction 32 (4), 337-367.

Gibson, J. J. (1979). The Ecological Approach to Visual Perception. Boston: Houghton Mifflin.

Goffman, E. (1979). Gender Advertisements. London: Macmillan.

Goffman, E. (1981). Forms of Talk. Philadelphia: University of Philadelphia Press. 
Goodwin, C. (1981). Conversational Organization: Interaction between Speakers and Hearers. New York: Academic Press.

Goodwin, C. (1994). Professional vision. American Anthropologist 96 (3), 606-633.

Goodwin, C. (2001). Practices of seeing visual analysis: an ethnomethodological approach. In T. van Leeuwen and C. Jewitt (Eds.), Handbook of Visual Analysis, pp. 157-182. London: Sage.

Goodwin, C. and M. H. Goodwin (1996). Seeing as situated activity: formulating planes. In Y. Engeström and D. Middleton (Eds.), Cognition and Communication at Work, pp. 61-95. Cambridge: Cambridge University Press.

Greatbatch, D., P. Luff, C. Heath, and P. Campion (1993). Interpersonal communication and human-computer interaction: an examination of the use of computers in medical consultations. Interacting With Computers 5 (2), 193-216.

Greiffenhagen, C. (forthcoming). Unpacking tasks: the fusion of new technology with instructional work. Forthcoming Computer Supported Cooperative Work (CSCW).

Gurwitsch, A. (1964). The Field of Consciousness. Pittsburgh, PA: Duquesne University Press.

Heath, C. (1986). Body Movement and Speech in Medical Interaction. Cambridge: Cambridge University Press.

Heath, C., M. Jirotka, P. Luff, and J. Hindmarsh (1995). Unpacking collaboration: the interactional organisation of trading in a city dealing room. Computer Supported Cooperative Work (CSCW) 3 (2), 147-165.

Heath, C. and P. Luff (1992). Collaboration and control: crisis management and multimedia technology in London underground line control rooms. Computer Supported Cooperative Work (CSCW) 1 (1-2), 69-94.

Heath, C., P. Luff, D. vom Lehm, J. Hindmarsh, and J. Cleverly (2002). Crafting participation: designing ecologies, configuring experience. Visual Communication 1 (1), 9-33.

Herring, S. C. (1999). Interactional coherence in CMC. In Proceedings of the 32nd Hawaii International Conference on System Sciences. Available at http://csdl.computer.org/comp/proceedings/hicss/1999/0001/02/00012022.PDF (accessed January 1, 2007).

Hester, S. and D. Francis (2003). Analyzing visually available mundane order: a walk to the supermarket. Visual Studies 18 (1), 36-46.

Jayyusi, L. (1993). The reflexive nexus: photo-practice and natural history. Continuum: The Australian Journal of Media \& Culture 6 (2), 25-52.

Jefferson, G. (1972). Side sequences. In D. Sudnow (Ed.), Studies in Social Interaction, pp. 294-338, New York: Free Press.

Jefferson, G. (1974). Error correction as an interactional resource. Language in Society 2, 181-199.

Jewitt, C. (2002). The move from page to screen: the multimodal reshaping of school English. Visual Communication 1 (2), 171-195.

Luff, P., N. Gilbert, and D. Frohlich (Eds.) (1990). Computers and Conversation. London: Academic Press. 
Luff, P. and C. Heath (1993). The practicalities of menu use: improvisation in screenbased activity. Journal of Intelligent Systems 3 (2-4), 252-296.

Macbeth, D. H. (2004). The relevance of repair for classroom correction. Language in Society 33 (5), 703-736.

Norris, S. (2002). The implication of visual research for discourse analysis: transcription beyond language. Visual Communication 1 (1), 97-121.

Rose, G. (2001). Visual Methodologies: An Introduction to the Interpretation of Visual Materials. London: Sage.

Sacks, H. (1975). Everyone has to lie. In M. Sanches and B. G. Blount (Eds.), Sociocultural Dimensions of Language Use, pp. 57-79. New York: Academic Press.

Sacks, H. (1992). Lectures on Conversation (Edited by G. Jefferson). Oxford: Blackwell.

Sacks, H. and E. A. Schegloff (1979). Two preferences in the organization of reference to persons in conversation and their interaction. In G. Psathas (Ed.), Everyday Language: Studies in Ethnomethodology, pp.15-21. New York: Irvington.

Sacks, H., E. A. Schegloff, and G. Jefferson (1974). A simplest systematics for the organization of turn taking in conversation. Language 50 (4), 696-735.

Schegloff, E. A. (1984). On some gestures' relation to talk. In J. M. Atkinson and J. Heritage (Eds.), Structures of Social Action: Studies in Conversation Analysis, pp. 266-296, Cambridge: Cambridge University Press.

Schegloff, E. A. (1992). Repair after next turn: the last structurally provided defense of intersubjectivity in conversation. American Journal of Sociology 97 (5), 12951345.

Schegloff, E. A. (2000). When 'others' initiate repair. Applied Linguistics 21 (2), 205-243.

Schegloff, E. A., G. Jefferson, and H. Sacks (1977). The preference for selfcorrection in the organization of repair in conversation. Language 53 (2): 361382.

Schenkein, J. (1971). Some Methodological and Substantive Issues in the Analysis of Conversational Interaction. Ph.D. thesis, University of California, Irvine.

Schenkein, J. (Ed.) (1978). Studies in the Organization of Conversational Interaction. New York: Academic Press.

Sharrock, W. and W. Coleman (2000). It don't mean a thing: on what computers have to say. Communication \& Cognition 33 (1/2), 83-95.

Van Leeuwen, T. and C. Jewitt (Eds.) (2001). Handbook of Visual Analysis. London: Sage.

Watson, D. R. (1987). Interdisciplinary considerations in the analysis of pro-terms. In G. Button and J. R. E. Lee (Eds.), Talk and Social Organisation, pp. 261-289. Clevedon: Multilingual Matters. 
(a) Interface of kar2ouche

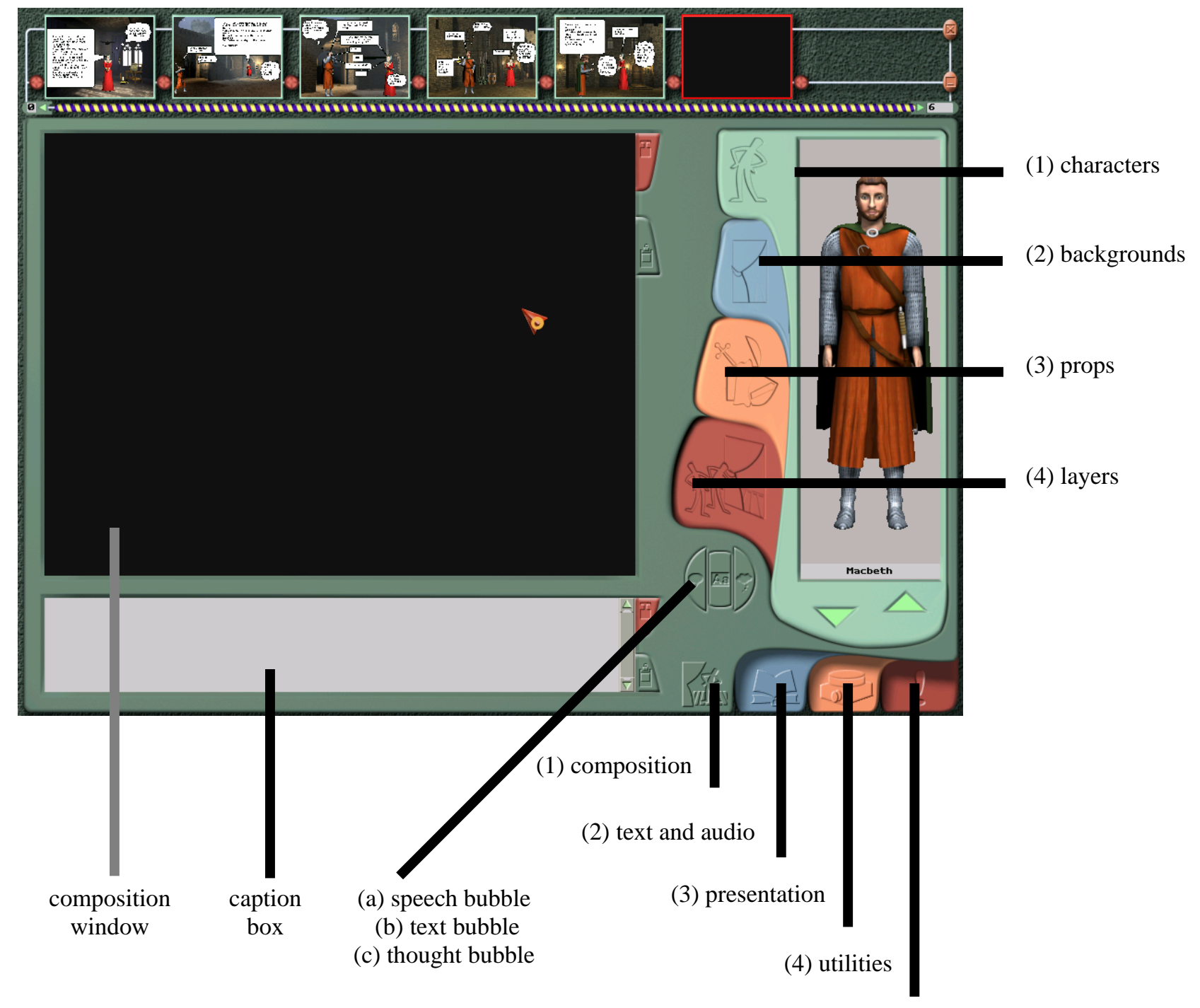


(b) Fragment 1: "you can't do it like that"

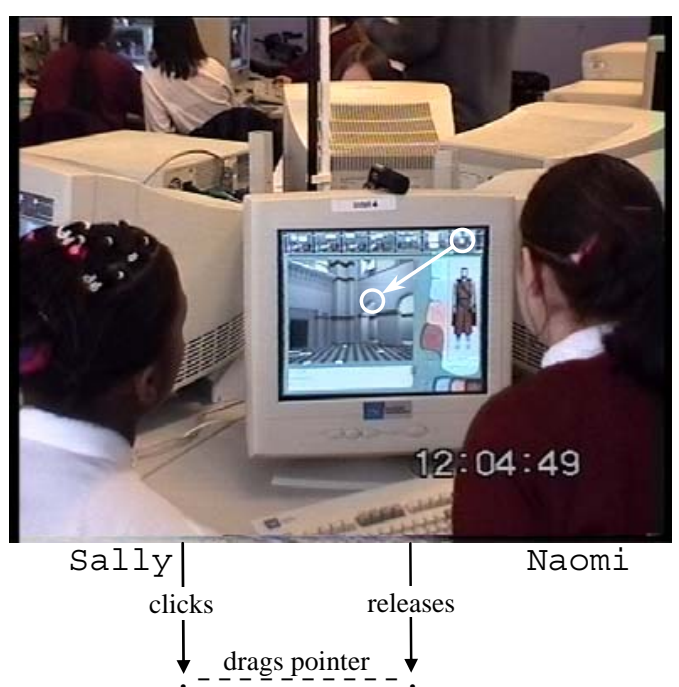

1 Naomi:

ts get Yyou down here $(---+---+---+--)$ oh no you can't do
2 Naomi: it like that (--) can Tyah (-------) oh de: ar Sally: huh huh

3 Naomi: ((drags Macbeth across from the character window)) 


\section{(c) Fragment 2: "load-save"}

1 Teacher: ((to the whole class)) five minutes left (.) five minutes (.) did you sa:ve?
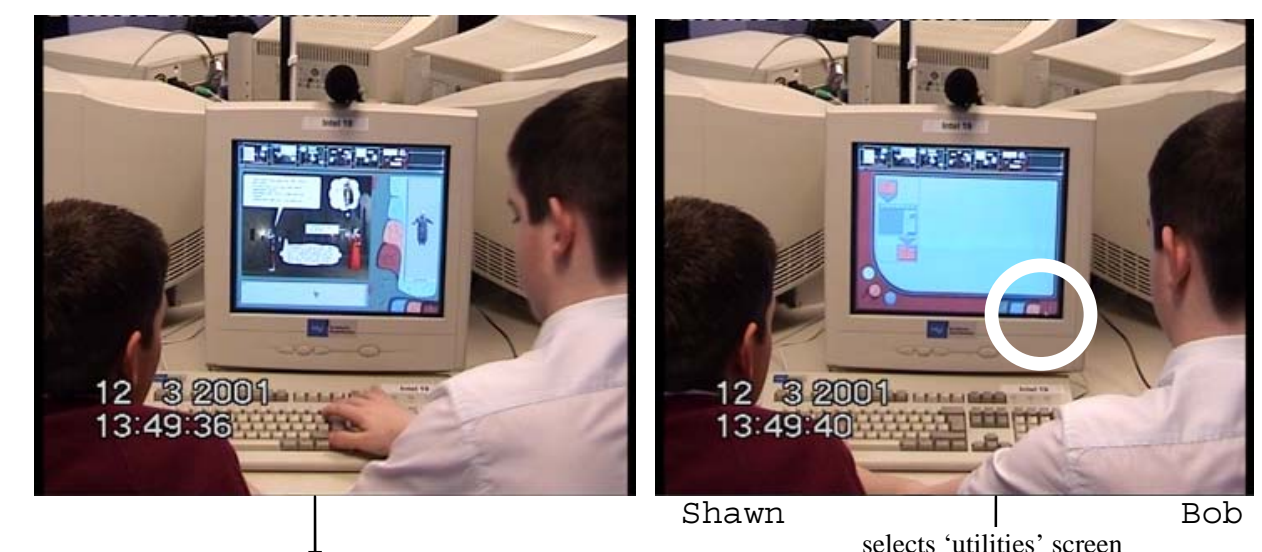

2 Bob: ((typing))

Shawn: >save (.) save now (.) save now (.) quick (.) please do not crash on us (----+)
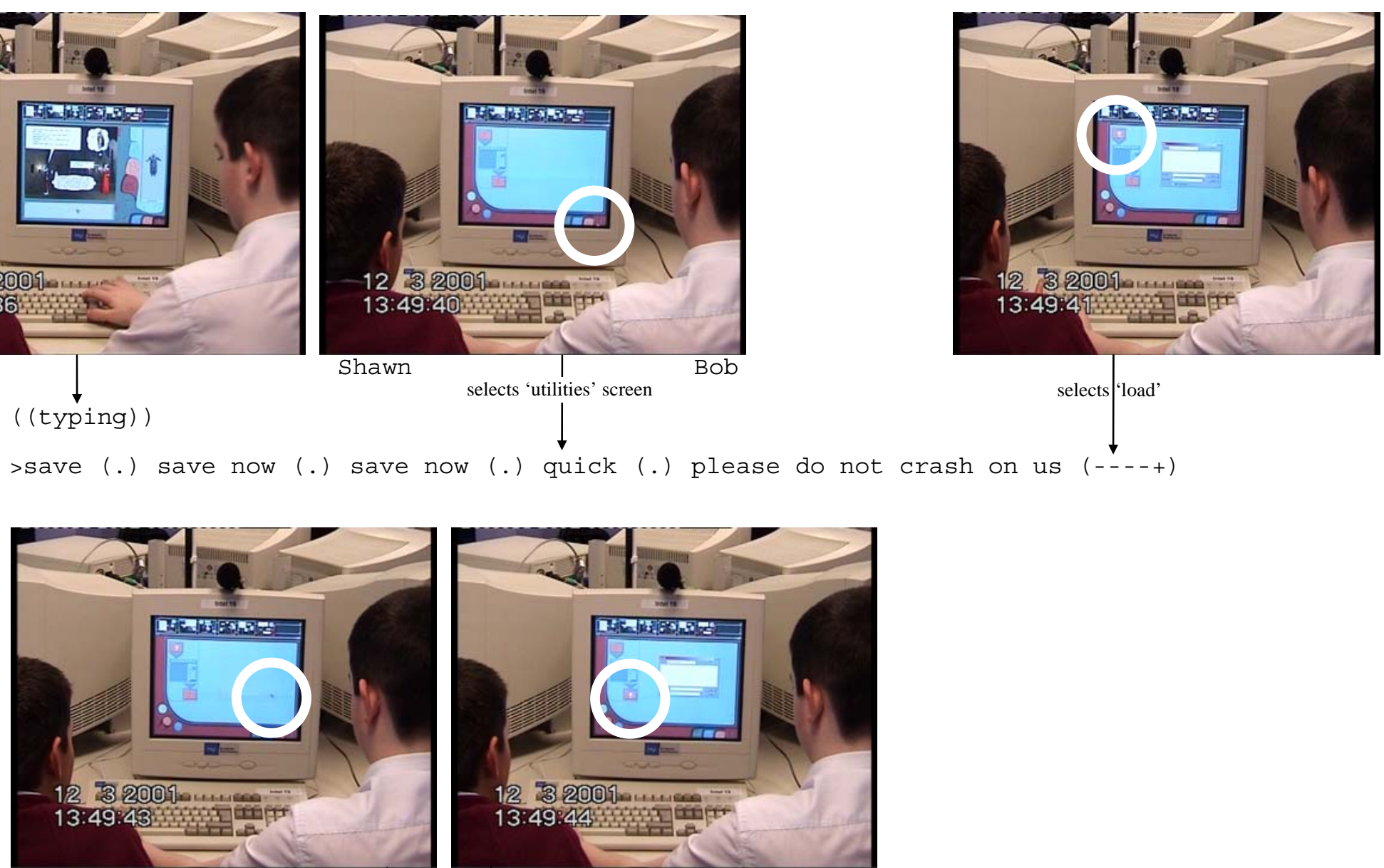

presses 'cancel'

3 Bob:

Shawn:
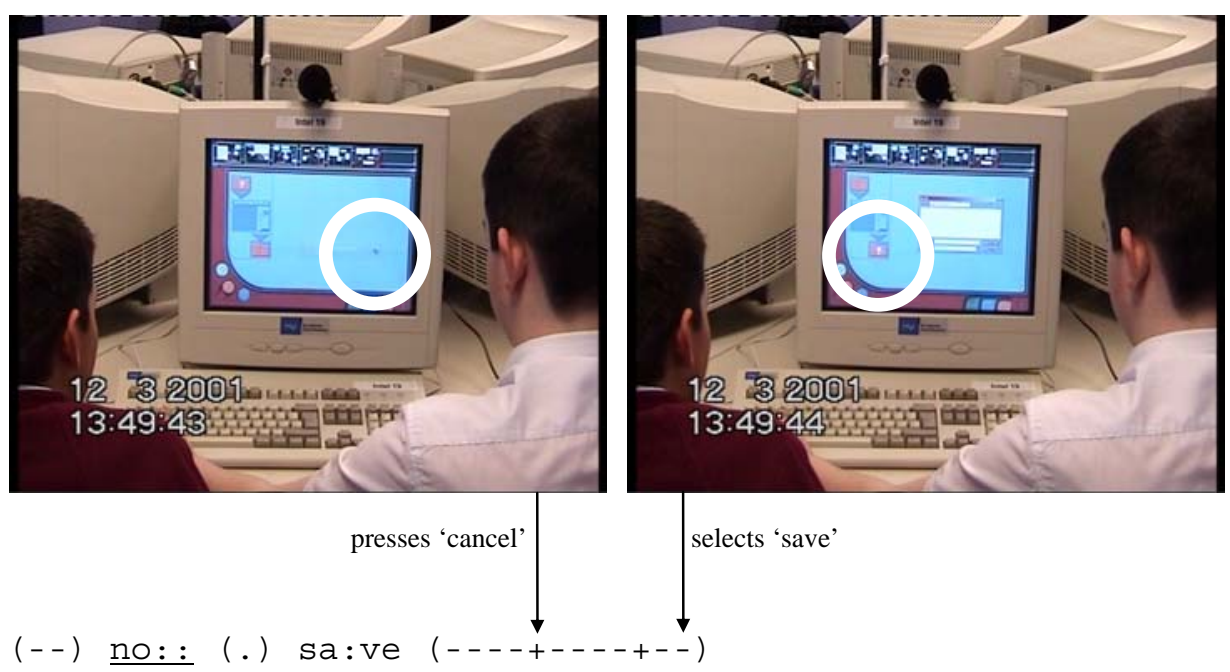

selects 'save'

$-)$ 
(d) Fragment 3: "poor past"
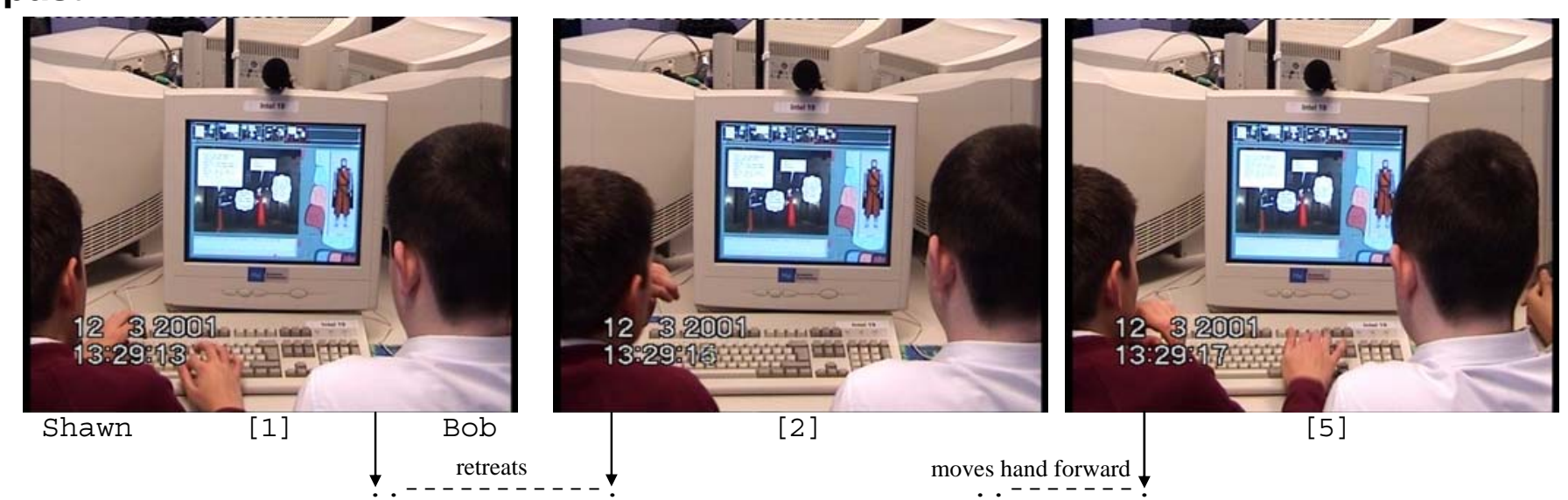

types:

$r \square$

p a s t $\square$

1 Shawn:

+) poo: :r

--) past

Bob :

Is that $\uparrow$ it

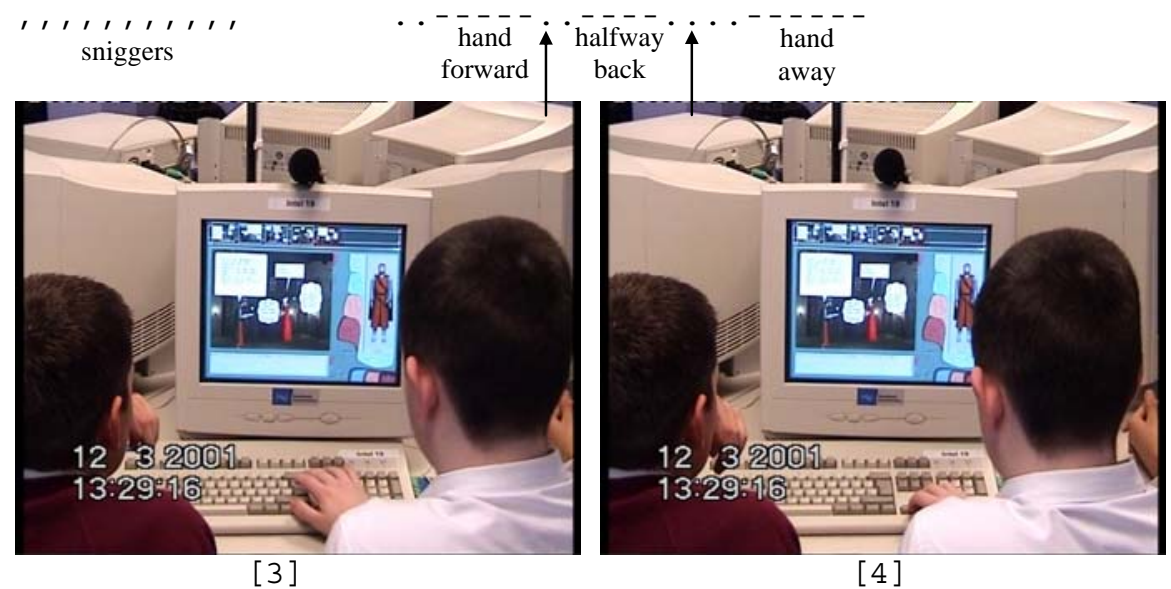

Macbeths is guilty and he knows it. Lady Macbeth is reflecting on her poor past I

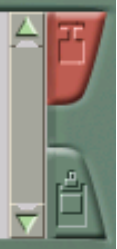


(e) Fragment 4

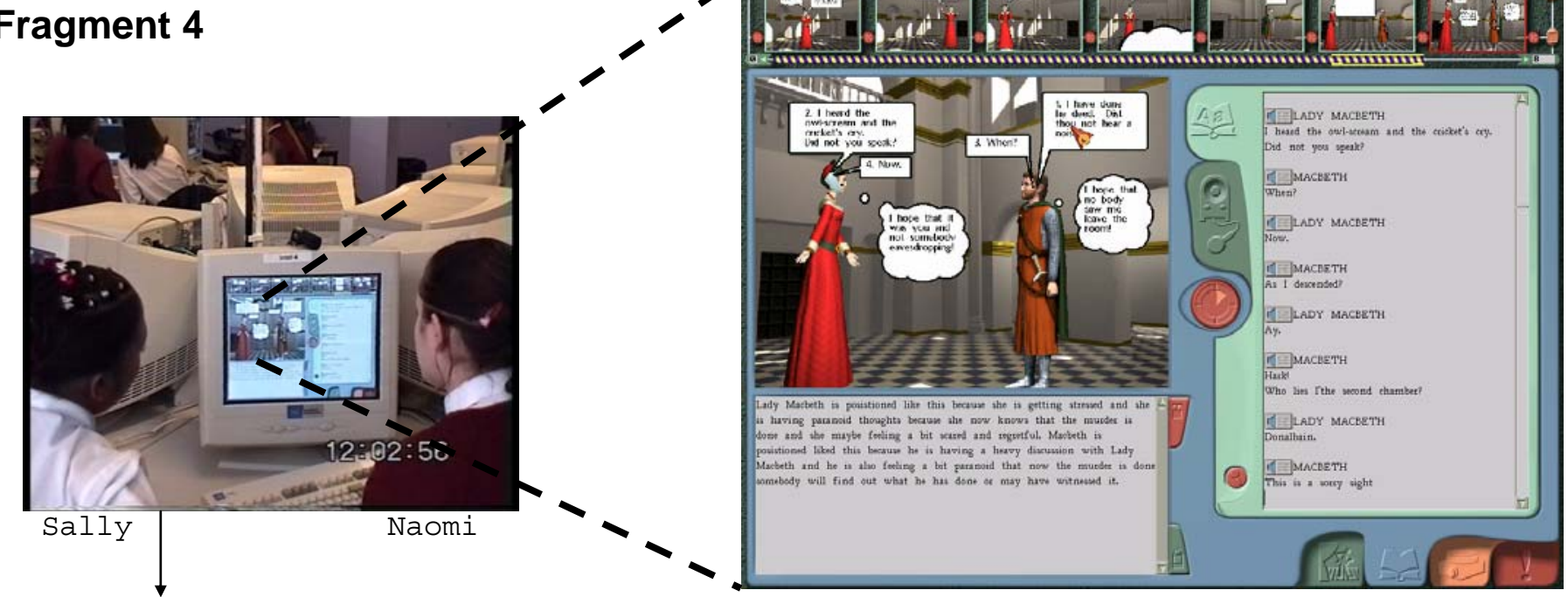

1 Naomi:

Wo $\uparrow$ wo: w wow wow now

) okay

- )

sally:
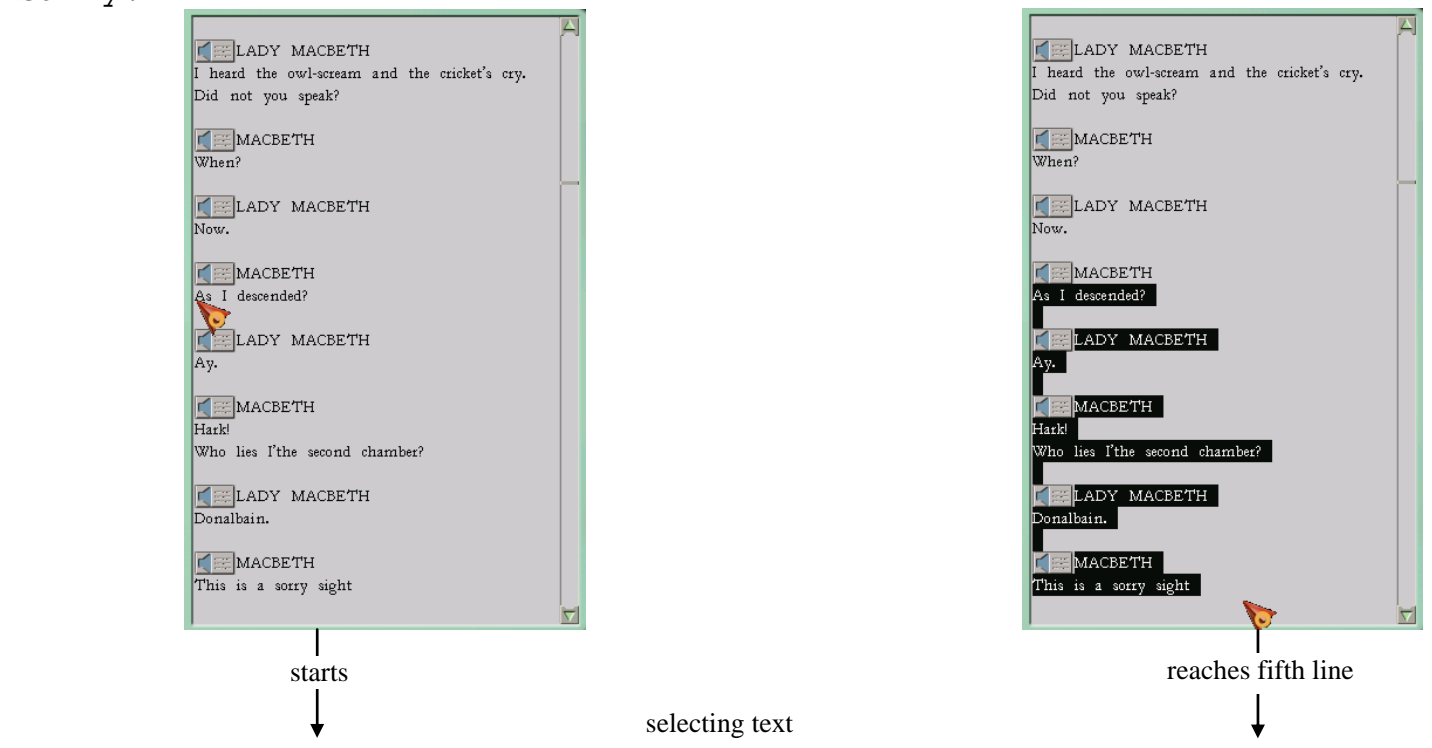

which is what I said $(---+)$

selecting text

reaches fifth line

2 Naomi: $(---+)$ I kno:w $(---+--)$

[

Sally:

You waste time you don't do that much (----+---+)

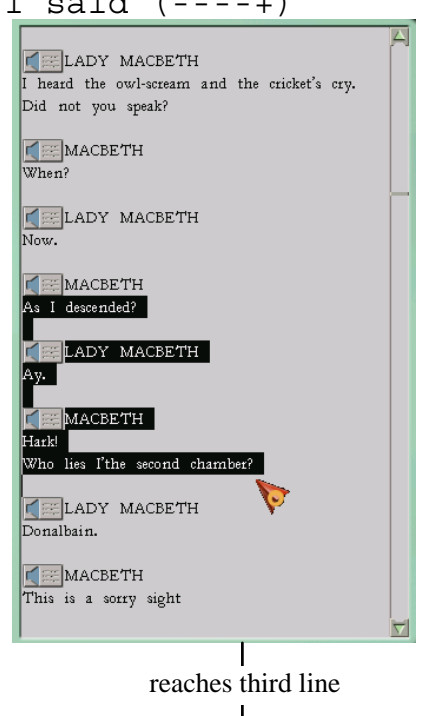




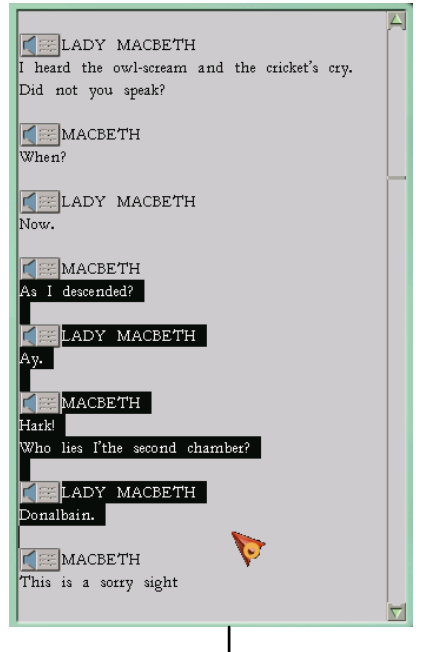

reaches fourth line selecting text $\downarrow$
3 Naomi:

Sally:

\begin{abstract}
this $\uparrow$ one
\end{abstract}
four

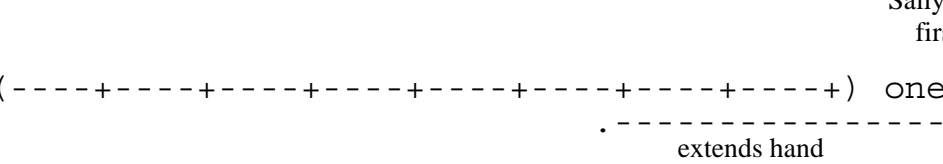

extends hand

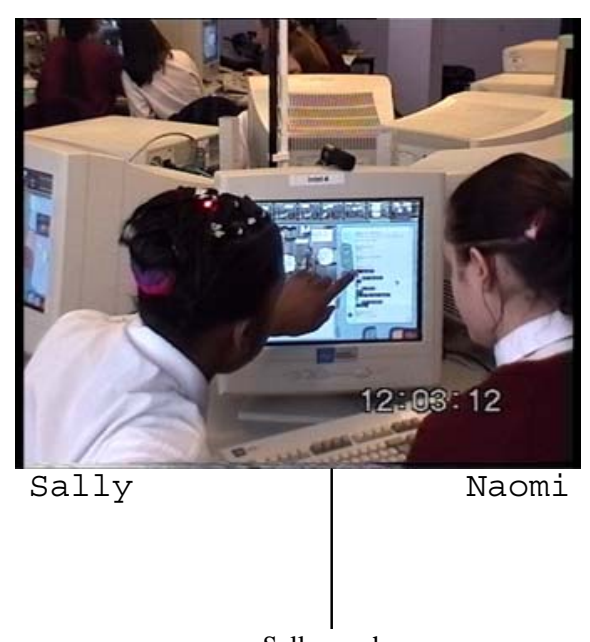

Sally reaches first line

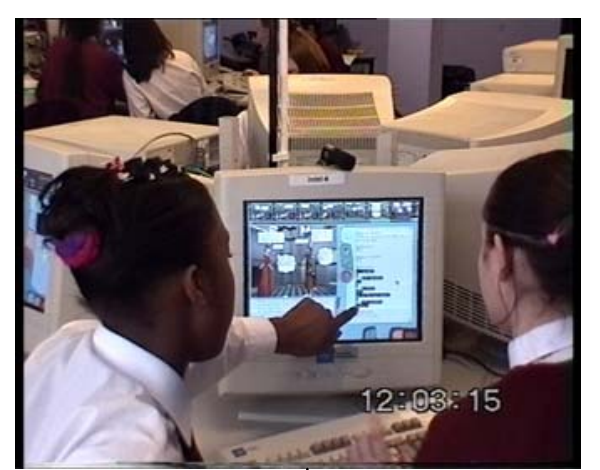

Naomi presses CTRL+C

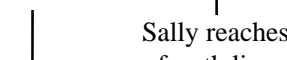

Sally reaches
fourth line

three (---) four counting

scrolling through the text

4 Naomi :

Sally: 